and more looping (Captain Cook, Australian cockatoos, the Permian extinction, the prospect of 9 billion humans, the Irish Republican Army, California's abalone, Newton, Funafuti Atoll in Tuvalu...).

Finally, he explains his pessimism: "The world of coral gives more reason for despondency than for hope. Local conservation can do little in the face of global change. The future of the reefs is bleak indeed. Their end presages a catastrophe that will spread far beyond their bounds - and remind us that we too are far from safe."

Daniel Pauly is director of the Fisheries Centre, University of British Columbia, Vancouver, British Columbia V6T 1Z4, Canada.

\title{
Unearthing gender issues
}

\section{The Invisible Sex: Uncovering The True \\ Roles Of Woman In Prehistory \\ by J. M. Adovasio, Olga Soffer \& Jake Page \\ HarperCollins: 2007.320 pp. \$26.95}

\section{Pat Shipman}

The Invisible Sex is a refreshing book that opens with a crucial reminder: "science is not truth; it is, instead, a method for diminishing ignorance." The authors - two well-known anthropologists (Jim Adovasio and Olga Soffer) and a science writer (Jake Page) - set out to diminish readers' ignorance about the human past, using a breezy, colloquial style that only occasionally irritates.

Their main point is that the male-dominated science of anthropology has usually chosen to interpret the evidence of the human past by basing it on male-dominated stereotypes. The authors succeed admirably in heightening the readers' awareness of such practices and in countering these stereotypical presentations with imaginative and equally defensible reinterpretations of particular sites or bodies of evidence. The end result helps to flesh out a more plausible female role in prehistory than has been offered previously. In many ways, this book is a much-needed antidote to the past hundred years of popular and scientific writing on prehistoric human life, and avoids the clichéd pitfall of veering too far into a hyper-feminist view.

The authors make many palpable hits. For example, they remark on the assumption that Lucy, the first largely complete Australopithecus to be found, was identified as female because the bones were small, not because they were diagnostically female. Similarly, they deconstruct the beautiful diorama at the American Museum of Natural History in New York of two australopithecines walking across the Laetoli plains, which are covered in damp volcanic ash, about 3.3 million years ago. A male and female walk together companionably, his arm around her shoulders. The female's head is turned, giving the impression that she is looking at the viewer, while the male remains focused on what lies ahead. The subtext of this depiction emphasizes the intimacy of their closely spaced footprints with the familiarly possessive/romantic gesture of a male arm around the female's shoulders. What would fit the evidence just as well - and echo many more observations of primate social behaviour - would be that the footprints were made not by a 'couple', but by a female and her juvenile offspring. Why choose one over the other?

Another target for scepticism is the supposed dominance of a hunting lifestyle among hominins. This idea ranged from Raymond Dart's lurid osteodontokeratic hypothesis - that bones, teeth and horns were used with minimal alteration by early hominins as tools for slaughtering animals and possibly each other - through the presentation of early, tool-making Homo ergaster in East Africa as a hunter rather than a scavenger. This 'man the hunter' stereotype lingers in images of the mighty, mammoth-slaughtering PalaeoIndians in North America. And yet, the authors argue, the mere existence of tools does not prove that hunting was important, much less that it was the mainstay of hominin survival or a predominantly male activity.

Such biases of the prehistoric record are common, especially with regard to the oldest sites. The authors aver that in recent dry cave sites, fibre artefacts outnumber stone ones by a factor of 20 to 1 . In several other situations, fibre and wood artefacts have been found to account for $95 \%$ of all artefacts recovered. That amounts to a tremendous amount of information not available to archaeologists in most parts of the world.

These are stunning observations that remind anthropologists that what we see is a tiny fraction of what might once have been present, not only in terms of individual animals but also in terms of artefacts. Many of those 'lost' artefacts may been essential aids to gathering, capturing small (not heroically large) animals, or modifying the world (building nests or brush shelters) in ways that do not involve obtaining food.

The authors also review the fascinating discovery by Adovasio and Soffer of fibre impressions on the clay fragments at Dolni Vestonice I in the Czech Republic. These attest to the existence of eight different weaving techniques, sewing, net-making and basketry, providing a startling new glimpse of life 26,000 years ago. They suggest that fibre arts had been a welldeveloped industry for some time before the formation of that site.

Making things out of fibre is not the sole prerogative of either sex in ethnographic accounts, the authors point out. But throughout the tribal world today, women make most of the basketry. The making of ceramics items, especially pottery, is chiefly the province of women. So, they

claim, it is safe to assume that most, if not all, of the ceramics, weaving, basketry and clothing was made by women in the years that Dolni Vestonice and the other Moravian sites were inhabited.

This is an astonishing leap of faith for those who have advocated a greater appreciation for the variability and malleability of gender roles elsewhere in the book. The interpretations offered by the authors are no more convincing than the standard ones, primarily because their interpretations are based on ethnographic and behavioural analogies that are different from, but not demonstrably sounder than, those they criticize.

Unfortunately, they never grapple with the central and most difficult questions of all. For example, when is it justifiable to draw on behavioural analogies from modern humans to interpret the past? When ought we to rely on behaviours of non-human primates or other mammals instead? And how are we to evaluate 
the relative probability of past behaviours when modern behaviours are so variable? Having pointedly raised these issues, the book disappoints because it does not offer any principles for doing a better job of reading the past.

The book is also flawed by appallingly poor attention to fact-checking. The authors misplace Olduvai Gorge and Laetoli in Kenya (they are in Tanzania); they call Mary and Louis Leakey palaeontologists instead of archaeologists; they cite Homo as the first of "what could at the time be called the hominid [hominin] line" (a grossly inaccurate remark because australopithecines are also hominins or hominids); and they mistakenly state that the carbon isotopes that distinguish grasseaters from tree-eaters are ${ }^{14} \mathrm{C}$ and ${ }^{13} \mathrm{C}$, rather than ${ }^{13} \mathrm{C}$ and ${ }^{12} \mathrm{C}$.

Unforgiveably, there are no notes in the book to identify the sources of either direct quotations or specific points of information. These glaring defects undercut the credibility of this otherwise intelligent and provocative work. Pat Shipman is adjunct professor of anthropology, Pennsylvania State University, 315 Carpenter Building, University Park, Pennsylvania 16802, USA.

\section{When the numbers don't add up}

\section{Useless Arithmetic: Why Environmental Scientists Can't Predict the Future by Orrin Pilkey \& Linda Pilkey-Jarvis Columbia University Press: 2007. 230 pp. $\$ 29.50, \pm 19$}

\section{Roger Pielke Jr}

The central thesis of Useless Arithmetic, by the father-and-daughter team of Orrin Pilkey and Linda Pilkey-Jarvis, is "the virtual impossibility of accurate quantitative modelling to predict the outcome of natural processes on the Earth's surface". This is sure to cause cognitive dissonance among many readers - it simply does not seem to accord with our lived experience.

As I write this review, I'm sitting on an aircraft safely crossing the United States. The plane was created with quantitative aeronautical engineering design models, its flight path dictated by quantitative routing models, and the snowy weather I experienced at takeoff was predicted by quantitative weatherforecasting models. Such experiences in successfully predicting and managing natural processes would seem to indicate that without mathematical models our twenty-first-century lives would simply be impossible. What could have influenced the authors to make claims so strongly contradicted by experience?

The authors answer this question unambiguously and definitively by discussing some two dozen instances (seven of which are examined in detail) in which decision-making, and in some cases science, based on mathematical modelling has gone awry, leading to undesired societal and environmental outcomes.

The difference between my flight and failed predictions and mismanagement of fisheries, say, is an important part of the book's argument. In engineering design, flight-path routing and weather prediction, quantitative models are produced and used in a different way from those used by policy-makers for fisheries management, sea-level rise, beach nourishment and the disposal of nuclear waste. However, many of the nuances and complexities involved in understanding these differences are hard to discern in the high-level, non-technical overview provided in Useless Arithmetic. For example, the book hints at the contextual importance of open and closed systems, consolidative and exploratory modelling, and epistemic (knowable) versus aleatory (random) uncertainties, but it does not provide the in-depth treatment needed to really understand these differences or their significance. Readers seeking to have their dissonance resolved may wish that the authors had explained these issues, rather than merely hinted at them. But those wanting more depth will find some useful pointers to accessible literature in a concise but useful bibliography.

The authors point out that modelling results "are easier to live with if they follow preconceived or politically correct notions", and the chapter on sealevel rise related to human-caused global warming seems to bear this out. In most chapters, the authors focus on a critique of models, modellers and model users. On climate change they choose instead to sandwich their critique of sea-level-rise models with an even stronger critique of Republican senator James Inhofe and author Michael Crichton, both of whom have strongly taken issue with the science of climate modelling and action on climate change. Yet the following authors' comments would have been equally at home in one of Inhofe's speeches or in Crichton's sceptical novel State of Fear (HarperCollins, 2004): "the juggernaut, the large industry that has risen to answer questions about global climate change, global warming, sea level rise, and all their ramifications, has unstoppable momentum... leaders in global change studies tend to view as a primary task the maintenance of funding for the modelling juggernaut." Have the authors lost their nerve when discussing the politically sensitive issue of climate change? Even so, their strong views on modelling in climate science are difficult to miss.

Despite these quibbles, this is a valuable book for the very reason that it causes dissonance. Using well-documented cases of policy failure, the authors have identified a critical challenge confronting the modern scientific enterprise: our ability to produce model-based predictions seems to have outpaced our ability to use such tools wisely in decision-making. The results are seen in bad policies and bad science.

So what to do? The authors' plea for a world without models is unrealistic, and not simply because scientists will continue to produce them. A story related by the Nobel prizewinning economist Kenneth Arrow explains why. As a weather forecaster in the Second World War, Arrow and his colleagues were

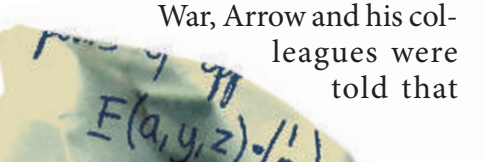

